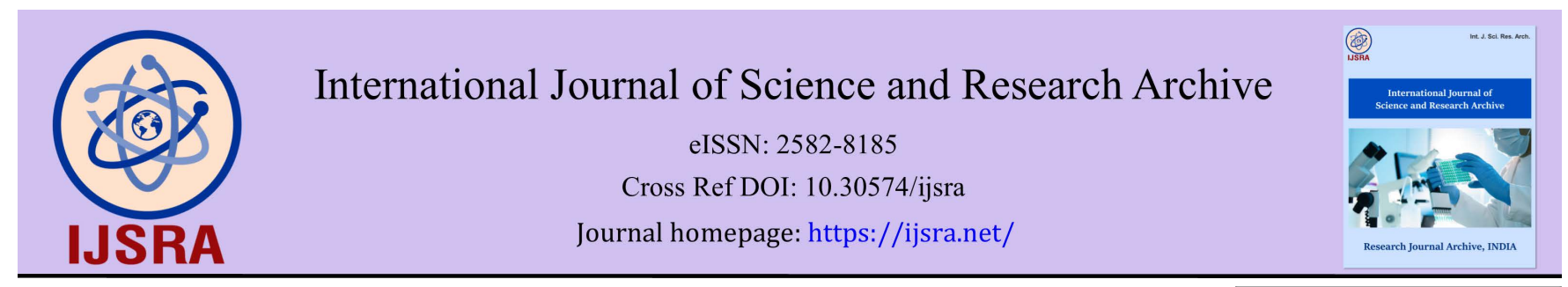

(RESEARCH ARTICLE)

Check for updates

\title{
Traumatic injuries due to road traffic accidents (RTA) involving motorized tricycles in Morocco
}

\author{
Omar Fadili *, Yassir El Andaloussi and Mustapha Fadili \\ Traumatology-Orthopedics and Reconstructive Surgery Department (Aile 4), Ibn Rochd University Hospital, Casablanca, \\ Morocco.
}

International Journal of Science and Research Archive, 2021, 03(01), 037-040

Publication history: Received on 11 June 2021; revised on 13 July 2021; accepted on 15 July 2021

Article DOI: https://doi.org/10.30574/ijsra.2021.3.1.0102

\begin{abstract}
Road Traffic Accident (RTA) are a major health problem in Morocco. Those involving rear cargo tricycles for passenger transport or mixed transport use require special attention. An 18-month continuous retrospective study was performed. It included all victims of RTA involving at least one tricycle, admitted to emergency department with a documented traumatic injury. The data collected was analyzed by statistical software (SPSS v18.0). The aim of this study was to assess the epidemiological, lesional and therapeutic characteristics of stroke's victims involving tricycles in the region of Grand Casablanca in Morocco. It also highlights the frequency and severity of injuries related to motorized tricycles accidents and the interest of regulatory enforcement to reduce the incidence of these accidents.
\end{abstract}

Keywords: Road Traffic Accidents; Tricycles; Morocco; Motorized; Traumatic; Injuries

\section{Introduction}

The tricycle is a three-wheeled motorized cargo vehicle. It was introduced massively in Morocco from the years 2010 to 2012 [1]. Used at the beginning for the transport of goods, it is also used as a taxi in some regions of the country in particular in Casablanca [2]. This use for public transport purposes exposes people to regulatory issues, to the youthfulness and recklessness of drivers and to serious traffic accidents.

Based on this observation, the aim of this study is to perform the epidemiological aspects, the specific lesional features and the therapeutic specificities of Road Traffic Accidents (RTA) involving tricycles in the city of Casablanca.

\section{Methods}

A 20-month continuous retrospective study from January 1, 2019 to August 30, 2020 was performed. The patients included were victims of RTA involving a tricycle and with documented traumatic injury. Deaths at the crash site were not included in the study.

The tricycle is a three-wheeled motorized rear cargo vehicle. The version involved in the AVP is a Chinese manufacture. It is a 200-250 cubic centimeter vehicle with a speed of up to $80 \mathrm{~km} / \mathrm{h}$ and a capacity of 2 to 3.5 tons [1].

Variables linked to trauma (socio-demographic, lesional, and therapeutic) and linked to trauma (position, mechanism, circumstance) were collected. The data collected was analyzed by statistical software (SPSS, v.18.0, Chicago: SPSS Inc.)

\footnotetext{
* Corresponding author: Omar Fadili

Traumatology-Orthopedics and Reconstructive Surgery Department (Aile 4), Ibn Rochd University Hospital, Casablanca, Morocco. Copyright $(2021$ Author(s) retain the copyright of this article. This article is published under the terms of the Creative Commons Attribution Liscense 4.0.
} 


\section{Results}

During the study period, 169 injured out of 4,805 were victims of a stroke involving at least one tricycle, ie $3.51 \%$ of trauma victims.

\subsection{Sociodemographic aspects}

The mean age of the patients was 31.18 years with extremes of 2 and 78 years. The most represented age groups were the second and third decade of life.

The male-to-female sex ratio was 2.31. The wounded came from poor conditions: commercial employees $(\mathrm{n}=30)$, farmers $(n=25)$, women employed in households $(n=25)$, students $(n=20)$, tricycle drivers $(n=9)$ and free workers $(\mathrm{n}=8)$.

\subsection{Traumatic circumstances}

Accidents occurred between 6 a.m. and 2 a.m. and a peak at 12 p.m.-2 p.m. Half of the accidents were of the tricyclemotorcycle type, a quarter of the "tricycle swerving" type and exceptionally of the tricycle-tricycle type. The injured person was willingly outside the tricycle (pedestrians, motorcyclists, etc.) (54.4\%), sometimes a passenger (25.4\%) or driver $(20.1 \%)$.

\subsection{Injury aspects}

The lesions encountered were diverse, mono or plurifocal. The head and lower limbs were the most exposed regions. The types of injuries ranged from isolated head trauma (drivers) to multiple trauma (passenger), including fractures and soft tissue injuries (pedestrians). The typical lesion of the driver was the open leg fracture $(n=5)$ (Figure 1) and maxillofacial lesions for passenger $(n=4)$.

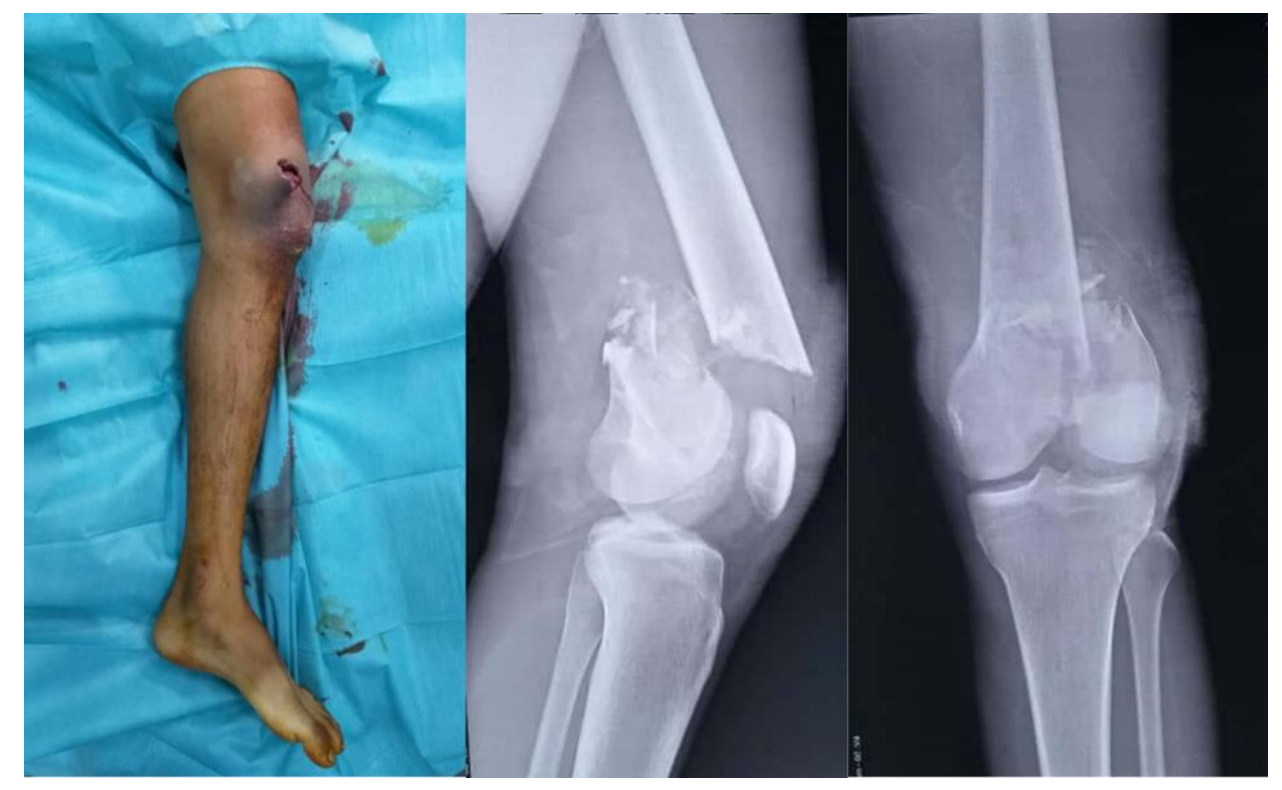

Figure 1 Open supra and inter condylar fracture of the left femur's lower extremity (Driver)

\subsection{Therapeutic aspects}

Seventy-seven patients were treated on an outpatient basis. Sixty-six others were hospitalized. In 24 cases, care was incomplete due to discharges against or without medical advice. The hospital lethality was eight. It concerned, among other things, three drivers of tricycles, three passengers including two children under the age of five. 


\section{Discussion}

RTAs involving motorcycle are commonly reported in Morocco and african countries [3]. These motorcycles are in fact bicycles. The use of motorized tricycles as taxis is common in Southeast Asia, the Indian subcontinent and some African countries such as Nigeria and Madagascar. Unlike our tricycles, they are covered vehicles, with limited places (two or three), a lower capacity of 200 to $300 \mathrm{~kg}$ and a lower speed [4,5].

The frequency of injured RTA victims involving tricycles in our series is to the credit of the context of poverty and porous legislation. The low-cost results in widespread use and the prospect of employment for low-skilled young men. Dangerous behaviors and the influence of psychotropic drugs favoring the occurrence of RTA [1].

The frequency of tricycle-motorcycle type RTAs is linked to the size of the national fleet of two-wheeled motor vehicles, recklessness and the condition of the roadways. The swerves of tricycles are explained by the overload (mixed transport of goods and people), the inexperience of the drivers (none of the drivers had a license and a third was under the age of 18) and the condition of machinery (no technical inspection) [1].

High velocity RCAs cause multifocal lesions. The head and lower limbs are exposed because they are less well protected. Outside the tricycle, the impacts are readily direct, such as crushing, compression, etc. and lead to limb fractures and

soft tissue damage. The passengers of the tricycle are thrown because the rear cargo is not covered. Without helmets, they are exposed to craniofacial injuries and multiple trauma. The driver of the tricycle is prone to injuries to the lower limbs such as open fractures of the legs or floating knees. Indeed, during an accident the lower limbs of the tricycle driver hit the pretibial bars of the machine. The impact on the bars results in an open leg fracture or an open floating knee in the leg [3].

Although the majority of the injured have received conventional care (87\%), it is incomplete for a large minority (13\%). The modest socioeconomic origin of the victims explains the sociological and economic barriers, especially in cases of bone damage $[1,3]$.

Hospital lethality is higher than the national average. The driver and young passengers are exposed. Failure to wear a helmet and hemorrhagic shock are the causes [3].

\section{Conclusion}

The high proportion of injured by RTA involving motorized tricycles is correlated with its high use. Awareness-raising against the use of tricycles as taxi-motorcycles should be promoted alongside the strict application of legal provisions and regulations.

\section{Compliance with ethical standards}

\section{Disclosure of conflict of interest}

None

\section{Statement of informed consent}

Informed consent was obtained from all individual participants included in the study. 


\section{References}

[1] Bennafla K. Le commerce transnational « informel », vecteur d'une nouvelle hiérarchie de lieux. L'exemple de la périphérie urbaine de Salé (Maroc). emam. 2015; 26.

[2] Modibbo JH, Mary FO. Impact of Commercial Tricycle Operation on Income of Youth in Mubi North Local Government Adamawa State Nigeria. 17.

[3] Madougou S, Chigblo PS, Tchomtchoua AS, Lawson E, Yetognon L, Hans-Moevi Akue A. Incidence et impacts des accidents de la voie publique chez les conducteurs de taxi-moto en milieu tropical. Revue de Chirurgie Orthopédique et Traumatologique. 2016; 102(2): 211-214.

[4] Guillen MDV, Ishida H. Motorcycle-propelled public transport and local policy development. IATSS Research. 2004; 28(1): 56-66.

[5] Odero W, Garner P, Zwi A. Road traffic injuries in developing countries: a comprehensive review of epidemiological studies. Trop Med Int Health. 1997 May; 2(5): 445-60. 